\title{
AINDA EM FAVOR DE UMA INTERFACE ENTRE SOCIOLINGUÍSTICA E GRAMATICALIZAÇÃO
}

\author{
STILL ON DEFENSE OF AN INTERFACE \\ BETWEEN SOCIOLINGUISTICS AND GRAMMATICALIZATION
}

À Edair Görski, com toda minha admiração e respeito.

\author{
Sebastião Carlos Leite Gonçalves | Lattes | sebastiao.goncalves@unesp.br \\ Universidade Estadual Paulista $\mid \mathrm{CNPq}$
}

Resumo: Neste artigo, insistimos na defesa de uma proposta de conciliação teórica-metodológica entre duas teorias linguísticas preocupadas com a mudança linguística - a Gramaticalização e a Sociolinguística -, destacando o pioneirismo da Linguística brasileira na elaboração dessa proposta, que passou a ser conhecida como "Sociofuncionalismo". Para tratar dos pontos de convergência e divergência entre Teoria da Gramaticalização e Teoria da Variação e Mudança Linguística, partimos dos trabalhos de Naro e Braga (2000) e de Görski e Tavares (2013, 200-?), por terem sido os primeiros a responderem questões relevantes que levariam ao trabalho de interface entre os dois modelos teóricos. Ilustramos essa proposta de conciliação com casos de perífrases verbais de aspecto cursivo que, resultantes de gramaticalização, podem ser abordadas sob perspectiva sociofuncionalista. Primeiramente testamos dois critérios de gramaticalização - frequência de uso e parâmetros de auxiliaridade - e depois mostramos os contextos de variação entre as perífrases, provando, assim, a pertinência da proposta.

Palavras-chave: Sociofuncionalismo. Gramaticalização. Variação. Perífrase verbal. Aspecto.

\begin{abstract}
In this paper, we insist on the defense of a theoretical-methodological conciliation proposal between two linguistic theories concerned with linguistic change - Grammaticalization and Sociolinguistics - highlighting the pioneering of Brazilian Linguistics in the elaboration of this proposal, which turned to be known as "Sociofunctionalism". To address the points of convergence and divergence between Grammaticalization Theory and Variation and Linguistic Change Theory, we start from
\end{abstract}


the Naro and Braga (2000) and Görski e Tavares' (2013) papers, since they were the first authors to answer relevant questions that would lead to the interface between these two theoretical models. We illustrate this proposal of conciliation with cases of grammaticalized cursive verbal periphrases that can be approached from a sociofunctionalist perspective. First, we test two grammaticalization criteria - frequency of use and parameters of auxiliarity - and then we show the contexts of variation between the periphrases. Therefore, we provide evidence for the relevance of this proposal.

Keywords: Sociofunctionalism. Grammaticalization. Variation. Verbal periphrasis. Aspect.

\section{Introdução}

Com as questões tematizadas neste artigo, presto minha homenagem a Edair Görski, uma das mais perseverantes defensoras do Sociofuncionalismo, uma terceira via teórica que procura conciliar pressupostos da Teoria da Gramaticalização, funcionalmente orientada (TG, daqui em diante) ${ }^{1}$, e a Teoria da Variação e Mudança Linguística (TVML, daqui em diante). Retomo esse tema aqui, porque ele é que me aproximou da homenageada no ano de 1999, quando, ainda aluno de doutorado, discutíamos com pesquisadores do PEUL (Programa de Estudos Sobre o Uso da Língua) questões de gramaticalização, tentando, naquele momento, estender seus limites para a consideração também de processos de articulação de orações (SCRIPTA, 2001). No início de 2003, tive a honra de tê-la entre os arguidores de minha tese de doutorado (GONÇALVES, 2003), defendida na Unicamp, em Campinas, sob orientação de Maria Luiza Braga. Daí em diante, construímos uma relação profissional pautada por uma admiração mútua que, além de estreitar nossos laços de amizade, nos permitiu interagir em diversas atividades acadêmico-científicas, incluindo bancas de defesa e eventos da área (PAIVA; GÖRSKI; GONÇALVES, 2015; GÖRSKI; GONÇALVES, LUCHESI, 2011). Neste texto-homenagem, insisto, portanto, num ponto: a necessidade de continuidade de trabalhos nessa interface teórica ainda válida e tão bem difundida pela homenageada.

A partir dos anos 1970, ao lado da TVML (WEINREICH; LABOV; HERZOG, 1968), em franca ascensão, outras correntes da Linguística, especialmente o Funcionalismo, passaram cada vez mais a dar enfoque na busca de correlações entre es-

\footnotetext{
${ }^{1}$ Em defesa do estatuto teórico da Gramaticalização (cf. Newmeyer, 2001), assumo aqui seu forte caráter de modelo explanatório das dimensões sincrônicas e diacrônicas da língua. Nessa mesma direção, Bybee (2016) argumenta que a Gramaticalização é capaz de fazer fortes previsões diacrônicas, com consequências profundas para a análise e descrição sincrônicas, e "Isso a torna uma teoria" (p. 180).
} 
trutura e uso da língua, o que forçosamente conduziu os estudiosos dessas outras correntes a também terem de considerar a variação como inerente ao sistema. A conjugação desses enfoques para melhor compreensão da relação entre sistema, uso e variação ordenada fez ressurgir entre funcionalistas o interesse pela TG - até então esquecida nos estudos da mudança linguística -, sob a concepção de que a língua é um sistema adaptativo complexo que exibe ao mesmo tempo estrutura, variação e gradiência e que nunca é produto acabado, mas sempre emergente do uso (HOPPER, 1987; BYBEE, 2016). Esse quadro teórico-metodológico ressurgido, também interessado na mudança linguística, vai encontrar pontos de convergência com a Sociolinguística Laboviana, mas também dela divergir em alguns aspectos.

No Brasil, a conciliação entre teorias sociolinguísticas e funcionalistas ecoa anos mais tarde, quando sociolinguistas labovianos, especialmente os ligados ao Grupo do PEUL (Programa sobre Estudos de Usos da Língua), começam, a partir dos anos 1980, a envidar esforços no tratamento de fenômenos variáveis, recorrendo a aspectos funcionais explicativos da variação e da mudança, momento em que a TG entra em cena com mais força, e o rótulo "Sociofuncionalismo" surge para evidenciar trabalhos que operam na interface entre as duas teorias (NEVES, 1999).

De modo mais fortalecido, a interface TG e TVML passa a se difundir entre linguistas brasileiros com o trabalho Naro e Braga (2000), no qual eles mostram pontos de acordo e de desacordo entre esses dois quadros. Na esteira de Naro e Braga (2000), seguiram os trabalhos de Tavares (2003) e, posteriormente, de Görski e Tavares (200?, $2013)^{2}$, que, ao assumirem declaradamente o termo "Sociofuncionalismo", vão às bases epistemológicas da TVML e da TG, para apontar, em detalhes, as similaridades entre seus postulados teórico-metodológicos, mas também os pontos de "difícil convergência ou mesmo divergentes" (GÖRSKI; TAVARES, 2013, p. 87). Essas questões de fundo podem ser recuperadas na tese de doutorado de Tavares (2003), que mostra, de modo consistente, como os elementos linguísticos e, aí, daí e então, de diferentes origens gramaticais, resultam em variantes de uma mesma variável, ao implementarem, por gramaticalização diacronicamente atestada, a mesma função discursiva de conectivos coordenadores de sequenciação retroativa-propulsora de informações.

Em termos de uma explicitação teórico-metodológica clara, essa empreitada as-

${ }^{2}$ GÖRSKI, Edair Maria; TAVARES, Maria Alice. Teoria da variação/mudança e funcionalismo linguístico: (in) compatibilidades? [200-?]. 30 p. Trabalho não publicado. A primeira versão desse trabalho circulou entre nós ao final dos anos 2000 e foi publicada, com alterações, como capítulo de livro (TAVARES; GÖRSKI, 2015); por isso, citamos aqui a versão original. Conciliando TG e TVML, são exemplos de outros trabalhos liderados por Görski, anteriores a 2013: Görski et al. (2002), Görski et al. (2003a), Görski et al. (2003b), Tavares e Görski (2006) e Görski (2008). 
sumida por linguistas brasileiros somente anos mais tarde passa a ser discutida a partir do quadro da TG. Fazemos, nesse passo, alusão aos trabalhos de Nevalainen e PalanderCollin (2011) e o de Poplack (2011) $)^{3}$, ambos publicados no The Oxford Handbook of grammaticalization (NARROG; HEINE, 2011), que reúne inúmeros trabalhos, cujos objetivos se voltam a mostrar como a TG pode ser tratada na interface não só com a TVML, mas também com diferentes outros quadros teóricos (Gramática Gerativa, Gramática de Construções, Tipologia Linguística, Aquisição de Linguagem, Língua de sinais etc.). Enquanto Nevalainen e Palander-Collin (2011) discutem a difusão da gramaticalização em diferentes dimensões da comunidade linguística (variação dialetal e variação demográfica), Poplack (2011) mostra como o método da TVML pode ser aplicado a processos de mudança identificados com a gramaticalização na sua versão mais ortodoxa, ou seja, na investigação de mudanças internas ao sistema. Ambos os trabalhos partilham da crença de que o uso da língua, sua variabilidade inerente e a gradualidade da mudança são pontos cruciais para a TVML e para a TG.

Voltando à proposta deste artigo, seu título pode sugerir certa extemporaneidade do tema, dados os desenvolvimentos recentes de teorias sociolinguísticas e funcionalistas. ${ }^{4}$ Insistir no tema, no entanto, remete-nos a uma agenda de pesquisa que, fortemente praticada no início dos anos 2000, procurou responder à crítica de que a TG, como teoria de mudança, nada mais seria do que um "conjunto distinto de leis da língua que operam independentemente da mente e do comportamento de seus usuários” (NEWMEYER, 2001, p. 191-192). Retomando, então, essa agenda de pesquisa, advogamos pela não dissociação de fatores sociais da explicação da mudança linguística. As versões recentes de abordagens funcionalistas da mudança identificadas com os Modelos Baseados no Uso (cf. TRAUGOTT; TROUSDALE, 2013, por exemplo) parecem minorar fatores sociais, sobretudo na explicação da formação/gramaticalização de construções procedurais, mesmo admitindo, como princípio, que uso, variação sincrônica e mudança diacrônica não se dissociam. ${ }^{5}$ Nessa nova abordagem, é consensual que, quanto mais interagem, mais os usuários tendem à padronização da variação, e o uso, como lócus da mudança, torna o falante fonte de micromudanças diacrônicas em seu próprio sistema e no de outros

\footnotetext{
${ }^{3}$ Observamos aqui que, já nos fins dos anos 1990, Poplack recorria à gramaticalização como explicação de fenômenos variáveis. Cite-se aqui, como exemplo, Poplack e Tagliamonte (1996).

${ }^{4}$ Não abordaremos aqui os desenvolvimentos recentes desses dois quadros teóricos. Ao leitor interessado, remetemos, no primeiro caso, aos trabalhos de Bybee (2016), Traugott e Trousdale (2013) e Trousdale (2014), e no segundo caso, ao trabalho de Eckert (2012).

${ }^{5}$ Referência deve ser feita, nessas ponderações, à Sociolinguística Cognitiva que, como extensão mais recente da Linguística Cognitiva, procura conjugar aspectos sociais da variação linguística e aspectos cognitivos por meio de métodos empíricos consistentes (SOARES DA SILVA, 2009).
} 
(BARLOW; KEMMER, 2001). Some-se a isso o fato de que a TG não está superada pela abordagem construcional da mudança, conforme se lê em Heine, Narrog e Long (2016), reconhecimento que alicerça nossa defesa do Sociofuncionalismo como proposta ainda atual. É sob tal justificativa que se assenta o objetivo mais específico do presente artigo: insistir na defesa do "casamento" acertado e consumado entre TG e TVML, em suas respectivas versões retratadas nos trabalhos seminais aqui citados, mostrando sua adequação, por meio de um estudo de caso de variação entre perífrases verbais gramaticalizadas no domínio funcional de aspecto.

Feita esta introdução, o presente artigo segue estruturado em duas outras seções principais. Na seção 2, apresentamos os pontos de convergência e de divergências entre TVML e TG, destacados por Naro e Braga (2000), e as bases epistemológicas que, recuperadas por Görski e Tavares (200-?, 2013), justificam esses pontos. Na seção 3, ilustramos as discussões dos autores, com um estudo de caso de perífrases verbais gramaticalizadas de aspecto imperfectivo cursivo, expondo a metodologia da investigação (3.1.), os resultados na esfera da TG (3.2.) e sua interpretação sob a égide da regra variável (3.3.). Ao final, seguem nossas considerações finais e as referências.

\section{Um diálogo eficiente entre TVML e TG}

A definição clássica de gramaticalização parte do reconhecimento da existência de propriedades prototípicas que distinguem léxico e gramática, não considerados como componentes estanques, mas difusos. Enquanto formas gramaticais incluem categorias funcionais cujos membros são mais ou menos fixos na gramática das línguas, formas lexicais constituem classes abertas que podem ser livremente modificadas por processos morfossintáticos. Como resultado de processos de gramaticalização, formas e construções lexicais passam a servir a funções gramaticais e, uma vez gramaticalizadas, podem desenvolver novas funções gramaticais (HOPPER; TRAUGOTT, 1993). O que se infere dessa definição é que, se, por um lado, a uma mesma forma linguística podem se associar diferentes graus de gramaticalização, por outro, formas gramaticais emergentes passam a concorrer com outras existentes, cuja obsolescência, se ocorre, apresenta causas independentes.

Na base dessa definição clássica, a gramaticalização deve primeiramente ser entendida como um processo histórico e gradual, o que não significa que não possa também ser abordada de um ponto de vista que considere a fluidez dos padrões sincrônicos da língua. Seja da perspectiva diacrônica, seja da sincrônica, o essencial a se reconhecer na 
gramaticalização é que formas submetidas a esse processo podem percorrer toda uma trajetória que as leva a assumir funções puramente gramaticais, típicas de processo de morfologização, ou podem instanciar apenas os primeiros passos desse processo de mudança, revelando casos incipientes de gramaticalização.

Esses aspectos essenciais da TG encontram amparo na concepção de "gramática emergente" (HOPPER, 1987), que enfatiza a existência de um fluxo intermitente e difuso entre as fronteiras que separam léxico e gramática. Sob essa concepção, Hopper (1991) propõe cinco princípios capazes de captar a natureza incipiente de processos de gramaticalização (Estratificação, Divergência, Persistência, Especialização e Descategorização), os quais, tomados conjuntamente, dão conta do reconhecimento de formas que ainda não se gramaticalizaram completamente como clítico ou afixo, mas que se encontram em um estágio em que a alteração categorial já é detectável. Desses princípios de Hopper (1987), interessa-nos destacar apenas dois, estratificação e divergência, os quais mais claramente permitem colocar em diálogo TG e TVML.

Segundo Hopper (1991), em processos de gramaticalização, estratificação e divergência devem ser assim compreendidas:

(i) Estratificação: num domínio funcional, novas camadas estão sempre emergindo, fazendo com que camadas novas e antigas coexistam num mesmo recorte temporal, como exemplificado em (1).

\section{(1) Estratificação no domínio funcional de futuridade}

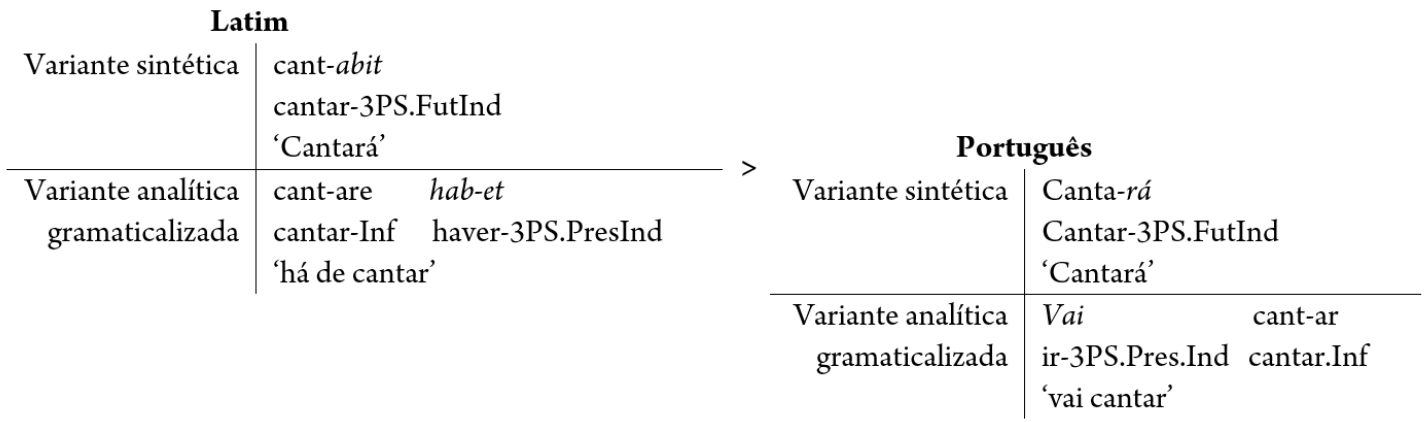

Fonte: Naro e Braga (2000, p. 129, com adaptação)

(ii) Divergência: quando uma forma se gramaticaliza, sua forma-fonte pode permanecer no sistema de modo autônomo e sofrer mudanças como um item lexical comum, como mostrado em (2). 


\section{(2) Divergência em usos de aí}

a. uso dêitico (menos gramaticalizado)

no que diz respeito a você, gostaria muito de te encontrar: aqui, aí, onde for, e conversar um pouco sobre o trabalho. (Correspondência pessoal - 25/05/2000)

\section{b. uso fórico}

F: ... melhor ano escolar meu, no Pedro II, foi a minha segunda quinta série. Que aí eu fiz sabe? numa- numa higiene mental. (LEO-01)

c. uso juntivo (mais gramaticalizado)

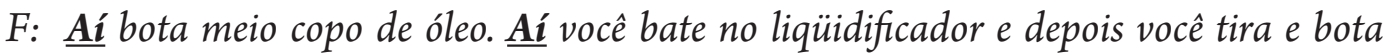
numa vasilha. (NA-01)

Fonte: Naro e Braga (2000, p. 128)

Enquanto, pela estratificação, apreendemos diferentes formas que, no mesmo domínio funcional, codificam função semelhante, pela divergência, apuramos diferentes funções de uma mesma forma. Ao cotejar o tratamento dado à variação linguística pela TG e pelo método da TVML, Naro e Braga (2000) destacam a pertinência desses dois princípios e, inicialmente, propõem o esquema em (3), explicativo da divergência.

\section{(3) Representação esquemática da divergência}

$$
a \rightarrow a / n(\rightarrow n)
$$

Fonte: Naro e Braga (2000, p. 128).

No esquema em (3), "a” representa a forma-fonte do processo de gramaticalização, "n", a forma nova resultante desse processo, e "n" entre parênteses, a segunda etapa de uma possível mudança diacrônica. Destacam os autores que, enquanto estudiosos da gramaticalização focalizariam as propriedades de "a" que podem fazer surgir "n" (p. ex., seus traços semânticos e traços particulares do contexto linguístico), variacionistas se centrariam, primeiramente, no estágio “a/n” e, secundariamente, nos estágios representados por "a" e "n", dadas as circunstâncias sociais favorecedoras ou não dos processos de mudança indicados pelas setas.

A questão inicial levantada por Naro e Braga (2000) é se poderia ser dispensado um tratamento de regra variável às formas distribuídas no continuum de gramaticalização representado em (3) (forma fonte "a”, forma nova " $n$ " e possíveis formas intermediárias “a/n"). A resposta inicial a esse questionamento, não tão óbvia em princípio, seria "não", 
porque as etapas do continuum corresponderiam a classes de palavras diferentes que não são mutuamente intercambiáveis.

Para tratar da estratificação, na busca do tratamento variável, os autores propõem o esquema representado em (4).

(4) Representação esquemática da estratificação

$$
a / f \rightarrow a / n / f
$$

Fonte: Naro e Braga (2000, p. 129).

No esquema em (4), "f" indica uma forma existente na etapa "a", não diretamente envolvida no processo de gramaticalização que gera "n" a partir de "a", o que significa que em uma etapa intermediária, existem duas fontes principais de formas coexistentes: "n", que, em vias de gramaticalização, coexiste com "a”, estrutura que gerou o próprio "n" (divergência), e "f”, que não participa diretamente da gramaticalização, mas que, como resultado do processo, passa a conviver com "n" (estratificação).

Tentando responder à questão de se formas estratificadas num mesmo domínio funcional podem ser consideradas variantes de uma mesma variável dependente, Naro e Braga (2000) apresentam o esquema geral do quadro da gramaticalização/variação de modo mais detalhado, como segue representado em (5).

\section{(5) Representação esquemática da gramaticalização/variação}

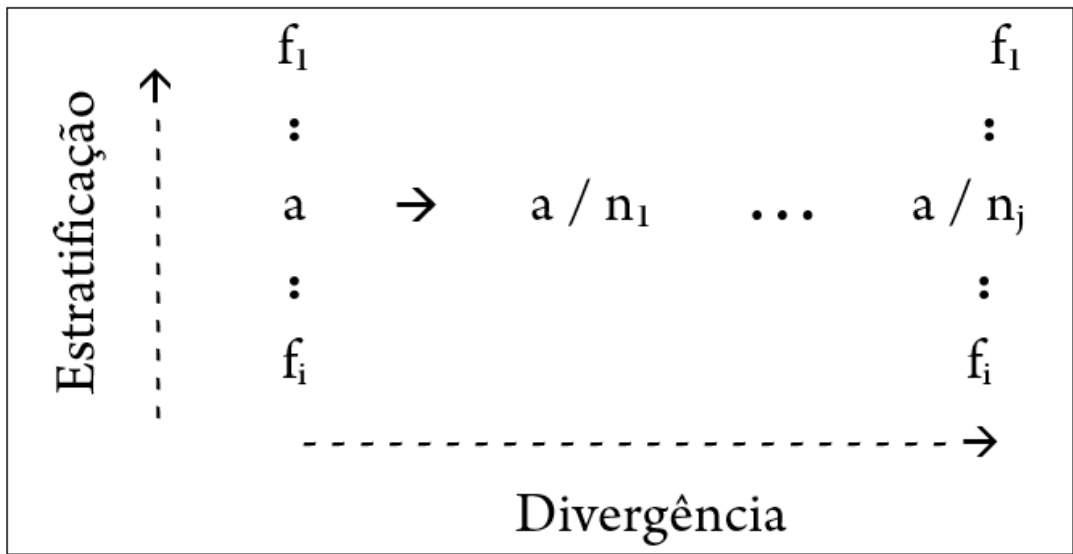

Fonte: Naro e Braga (2000, p. 130; com adaptação) 
No esquema em (5), os autores introduzem dois refinamentos: (i) na dimensão horizontal, os diferentes " $n$ " $\left(n_{1} \ldots n_{j}\right)$ representam estágios coexistentes do continuum da gramaticalização, captados pelo princípio da divergência; na vertical, os diversos " $f$ " $\left(f_{1} \ldots\right.$ $\mathrm{f}_{\mathrm{i}}$ ) representam estruturas anteriores coexistentes no mesmo domínio funcional, captadas pelo princípio da estratificação.

Em torno desse esquema em (5), que tenta conciliar variação e gramaticalização, a diferença fundamental para a TVML e a TG gira em torno da exigência de mesmo significado referencial entre formas alternantes, o que significa que tal exigência se cumpriria apenas sob a ótica do princípio da estratificação. Enquanto um estudo variacionista deve responder à premissa de equivalência no nível semântico entre as variantes, essa exigência é dispensada pelos estudos da gramaticalização, justamente porque a gramaticalização trata da criação de novas formas de expressão atuantes num mesmo domínio funcional. No entanto, Naro e Braga (2000), a exemplo de Lavandera (1978), recomendam que se adote o afrouxamento dessa exigência variacionista para que nuances de sentido possam ser controladas por variáveis independentes. Somente assim uma aproximação entre os dois modelos teóricos se torna possível.

Voltando à divergência, como reconhecem os autores, o próprio rótulo já mostraria inapropriada sua aplicação a uma abordagem variacionista, uma vez que tal princípio trata de significados divergentes para uma mesma forma. No entanto, como advertem, a resposta negativa a esse ponto requer antes que se considere que "no início do processo de gramaticalização nem tudo está tão claro" (p. 131) e que é preciso compreender que a divergência começa exatamente por uma reanálise estrutural da construção original que, até se gramaticalizar numa nova função, pode conviver com construções diferentes que cumprem a mesma função. São exemplos os casos de construção de movimento com propósito, mostrados em (6a), que, como fonte da gramaticalização de futuro (6b), podem admitir um estágio inicial em que estruturas diferentes (de movimento com propósito e de futuro) podem ter um mesmo sentido.

\section{(6) Reanálise estrutural na criação de construção de futuro}

a. Sujeito $[\text { be }+ \text { V. movimento }]_{\mathrm{Sv}} \quad[\mathrm{V} \text {. complemento }]_{\mathrm{sv}} \rightarrow$ movimento com propósito Tony [is going $] \mathrm{sv}$ [to give a lecture $] \mathrm{sv}$

b. Sujeito [be going to + V. complemento $]_{\mathrm{sv}} \quad \rightarrow$ futuro Tony [is going to give a lecture $\quad]_{\mathrm{sv}}$

Fonte: Naro e Braga (2000, p. 131, com adaptação) 
Por último, o ponto divergente essencial entre TVML e TG diz respeito ao tratamento da mudança. A maioria dos variacionistas aceita que toda mudança linguística pressupõe um estágio anterior de variação, mas nem toda variação conduz à mudança, no curto ou médio prazos, o que significa admitir que o sistema comporta variação estável. Os estudiosos da gramaticalização, por sua vez, explicam a coexistência de formas capazes de codificar uma mesma função como uma etapa de um longo processo, que pode tanto se interromper quanto levar ao desaparecimento da estrutura original. Assim, as duas abordagens têm pontos de partida e áreas de interesse distintos, como parece claro na proposta de Naro e Braga (2000).

Resumidamente, os autores sustentam que a variação decorrente da estratificação pode ser investigada à luz da metodologia quantitativa da TVML. Em se tratando, todavia, da variação que depende da aplicação do princípio de divergência, a situação é mais delicada. É provável, porém, que, nos estágios iniciais do processo de mudança, as duas formas divergentes possam ter o mesmo sentido, condição para a aplicação da reanálise das fronteiras de constituintes, como mostrado em (6).

Görski e Tavares (200-?, 2013) vão ao exame minucioso dos "pressupostos das abordagens teórico-metodológicas da Sociolinguística e do Funcionalismo” e apresentam o Sociofuncionalismo como uma terceira abordagem resultante da compatibilização de entre as duas teorias (GÖRSKI; TAVARES, 2013, p. 79). Como mostram, o valor atribuído à função e à estrutura revela as diferenças mais fundamentais entre as duas teorias, como apresentamos resumidamente no quadro 1.

Quadro 1 - Pontos de divergência ente TVML e TG.

TVML TG

Focaliza o sistema e a estrutura, visando à postulação de regras abstratas subjacentes ao uso. Portanto, a natureza funcional da língua (fatores de natureza funcional) é secundária.

As regras variáveis representam um modo de descrever formalmente a inter-relação sistemática entre os condicionamentos internos e externos à língua.

Focaliza a funcionalidade das estruturas no uso linguístico, não havendo necessidade de se estipularem regras abstratas subjacentes ao uso.

Padrões linguísticos fluidos permitem a (re)constituição da gramática, que é funcionalmente motivada. Situações comunicativas moldam a gramática e as relações, em diferentes graus, entre funções e formas que se alteram ao longo do tempo.

A pesquisa empírica é fortemente controlada, de modo a se postularem variáveis de natureza discreta que expliquem a variação e a mudança.

As categorias da língua são de natureza gradiente, e a noção de continuum é essencial na explicação da variação e mudança. $\mathrm{O}$ comportamento linguístico se explica entre categorias linguísticas (que se sobrepõem) e não na categoria em si.

Fonte: Elaboração própria, a partir de Görski e Tavares (200-?). 
Assumindo-se esses postulados em torno dos quais os dois quadros teóricos poderiam ser de difícil conciliação, uma aproximação entre eles começa a ser possível com a verificação, em mais detalhes, do modo como cada um concebe a variação e a mudança. Como destacam as autoras, o confronto dos pontos mostrados no quadro 2 a seguir, em torno dos quais poderia existir certa discordância entre TVML e TG, não chegam a impedir a busca de um imbricamento entre elas. Recorrendo a autores que são referências em cada uma das abordagens (WEINREICH; LABOV; HERZOG, 1968; LABOV, 1972, 1994; GIVÓN, 1979; HOPPER; TRAUGOTT, 1993; BYBEE; HOPPER, 2001), destacamos, de Görski e Tavares (2013), os postulados mostrados em (7), que, de modo cabal, permitem a conciliação entre os dois quadros teóricos.

\section{Pontos de convergência entre TG e TVML}

a. A prioridade atribuída à língua em uso (em situações reais de comunicação), cuja natureza heterogênea abriga a variação e a mudança.

b. A dinamicidade da língua (a língua está continuamente se movendo e mudando).

c. O Princípio do Uniformitarismo (LABOV, 1994), sob o qual sincronia e diacronia são perspectivas complementares para obtenção de prognósticos de mudança confiáveis.

d. A importância da frequência de uso, que, estatisticamente apurada, fornece evidências para a variação e mudança.

e. O entendimento da mudança linguística como um processo contínuo e gradual ao longo de espectros linguístico e social, com alterações contínuas em termos de frequência.

f. Os fenômenos de gramaticalização como fonte de explicação da variação e mudança morfossintática.

Fonte: Görski; Tavares (2013, p. 81-87, com adaptações). 
Quadro 2 - A variação e mudança na TVML e na TG.

\begin{tabular}{|l|l|}
\hline \multicolumn{1}{|c|}{ TVML } & \multicolumn{1}{|c|}{ TG } \\
\hline $\begin{array}{l}\text { Mudança é a disseminação da inova- } \\
\text { ção na comunidade de fala (e não a } \\
\text { inovação e suas causas em si) }\end{array}$ & $\begin{array}{l}\text { Mudança é tanto o surgimento das inovações quanto } \\
\text { sua propagação social. }\end{array}$ \\
\hline $\begin{array}{l}\text { Variação implica o reconhecimento } \\
\text { de diferentes formas para um mesmo } \\
\text { significado. }\end{array}$ & $\begin{array}{l}\text { A variação é captada no reconhecimento tanto na es- } \\
\text { tratificação de um domínio funcional quanto na diver- } \\
\text { gência de funções para uma mesma forma. }\end{array}$ \\
\hline $\begin{array}{l}\text { Mudança decorre da variação (formas } \\
\text { concorrentes para um mesmo signif-- } \\
\text { cado). }\end{array}$ & $\begin{array}{l}\text { Variação decorre da mudança (um item muda de sig- } \\
\text { nificado e passa a concorrer com outras formas). A va- } \\
\text { riação é pano de fundo. }\end{array}$ \\
\hline $\begin{array}{l}\text { A mudança é o ponto de chegada: uma } \\
\text { forma pode se especializar e suplantar } \\
\text { sua alternante. }\end{array}$ & $\begin{array}{l}\text { A mudança é o ponto de partida: ao se gramaticalizar, } \\
\text { uma forma passa conviver com outras num mesmo } \\
\text { domínio funcional. }\end{array}$ \\
\hline \multicolumn{2}{|c|}{ Ponto de imbricação } \\
\hline $\begin{array}{l}\text { Ao se gramaticalizar uma forma assume nova função, entrando em variação com formas antigas } \\
\text { na codificação daquela função (perspectiva da sociolinguística). }\end{array}$ \\
\hline $\begin{array}{l}\text { Capta uma etapa da gramaticalização } \\
\text { quando a variação se instaura. }\end{array}$ & $\begin{array}{l}\text { Capta diferentes etapas da variação ao longo do tem- } \\
\text { po. }\end{array}$ \\
\hline \multicolumn{2}{|c|}{ Formas variantes vs. Camadas funcionais } \\
\hline $\begin{array}{l}\text { Nem toda variação leva à mudança } \\
\text { (variação estável), mas toda mudança } \\
\text { decorre da variação (uma forma se es- } \\
\text { pecializa). }\end{array}$ & $\begin{array}{l}\text { Dentro de um domínio funcional, uma forma grama- } \\
\text { ticalizada não necessariamente suplanta a forma com } \\
\text { a qual passa a competir (variação estável). Uma pode } \\
\text { sofrer especialização (mudança) e iniciar novo ciclo } \\
\text { de gramaticalização. }\end{array}$ \\
\hline $\begin{array}{l}\text { A variação se resolve com o tempo, } \\
\text { quando uma regra variável se torna ca- } \\
\text { tegórica. }\end{array}$ & $\begin{array}{l}\text { A estratificação se resolve com o tempo, quando a for- } \\
\text { ma gramaticalizada pode vir a se especializar em detri- } \\
\text { mento de outras do mesmo domínio funcional. }\end{array}$ \\
\hline
\end{tabular}

Fonte: Elaboração própria, a partir de Görski e Tavares (200-?).

\section{Perífrases aspectuais [V $V_{1}$ ANDAR/CONTINUAR/FICAR/VIVER $+V_{2}$ NDO] na abordagem sociofuncionalista}

O fato de, na língua portuguesa, não haver morfemas gramaticais específicos para distinções aspectuais, como existem para a marcação de tempo e modo, pode explicar a existência de diferentes tipologias aspectuais e certo desacordo entre elas, conforme pode ser verificado no confronto das propostas de Castilho (1968, 2002), Travaglia (1981), Costa (2002) e Ilari e Basso (2008), para mencionar as principais. No entanto, um ponto consensual entre as diferentes propostas é o reconhecimento de perífrases verbais como recurso, por excelência, para codificação de valores aspectuais.

Um ponto a se destacar no funcionamento de grupos verbais com estatuto perifrástico diz respeito à natureza gramatical de $V_{1}$ na construção, o qual, ao se gramaticalizar, desenvolve função típica de verbo auxiliar. No entanto, critérios para sancionar a auxiliaridade de verbos em construções perifrásticas são vastos e pouco consensuais, chegando 
a ser possível apurar, na literatura, 25 parâmetros diferentes (cf. HEINE, 1993; LOBATO, 1975; LONGO; CAMPOS, 2002; ILARI; BASSO, 2008).

Em que pese o dissenso na Aspectologia, adotamos, neste trabalho, a tipologia defendida por Castilho $(1968,2002)$, também pelo pioneirismo de sua proposta para o português. De acordo com o autor, "o aspecto é a visão objetiva da relação entre o processo e o estado expressos pelo verbo e a ideia de duração ou desenvolvimento. É, pois, a representação espacial do processo" (CASTILHO, 1968, p. 14). Ou ainda: "é uma propriedade da predicação que consiste em representar os graus do desenvolvimento do estado de coisas aí codificado, ou, por outras palavras, as fases que ele pode compreender" (CASTILHO, 2002, p. 83). É do autor, a tipologia dada no quadro 3, da qual interessa a nossos propósitos destacar apenas a noção de aspecto imperfectivo cursivo.

Quadro 3 - Tipologia Aspectual

\begin{tabular}{|c|c|c|c|}
\hline Faces & Valores & \multicolumn{2}{|c|}{ Noções Aspectuais } \\
\hline Qualitativa & \multirow{2}{*}{$\begin{array}{c}\text { 1. Duração } \\
\text { (fasais) }\end{array}$} & Imperfectivo & Inceptivo \\
\cline { 4 - 4 } & $\begin{array}{c}2 . \\
\text { Completamento } \\
\text { (não-fasais) }\end{array}$ & Perfectivo & Terminativo \\
\cline { 3 - 4 } & \multirow{2}{*}{ Quantitativa } & Resultativo \\
\hline & \multirow{2}{*}{ 3. Repetição } & Iterativo & Imperfectivo \\
\cline { 3 - 4 } & & Semelfactivo & Perfectivo \\
\hline
\end{tabular}

Fonte: Castilho (1968, 2010, com adaptações)

O aspecto imperfectivo cursivo refere-se à duração de processos acerca dos quais não se reconhecem princípio nem fim, sendo eles apresentados em seu pleno desenvolvimento. Esse tipo aspectual tem como variantes o cursivo propriamente dito e o cursivo progressivo (que marca a gradualidade do processo), além da combinação possível com a noção de repetição (iteratividade) ou não (semelfactividade) do processo, a depender do tipo semântico de verbos envolvidos na construção perifrástica.

Por ora, é suficiente exemplificar essas nuances do imperfectivo cursivo, com os casos de perífrases formadas pelos $V_{1}$ auxiliares andar, continuar, ficar e viver, seguidos de verbo principal no gerúndio $\left(V_{2}\right.$ NDO $)$. Essas perífrases são constituídas a partir de um processo de gramaticalização de $V_{1}$ na construção perifrástica, principalmente pela sua dessemantização como verbo pleno. Como resultado desse processo, as diferentes cons- 
truções perifrásticas de aspecto cursivo coexistem na língua dentro de um mesmo domínio funcional, representando típico caso de estratificação. $\mathrm{O}$ reconhecimento dos valores aspectuais exemplificados de (8) a (11), no quadro 4, independe, em princípio, da flexão modo-temporal de $V_{1}$ (COSTA, 2002).

Quadro 4 - Ocorrências prototípicas de perífrases aspectuais $\left[V_{\text {I-ANDAR/CONTINUAR/FICAR/VIVER }}+V_{2_{-} \text {NDO }}\right]$

\begin{tabular}{|c|c|}
\hline Funções & Ocorrências prototípicas \\
\hline $\begin{array}{l}\text { (8) } \\
\text { Imperfectivo } \\
\text { cursivo } \\
\text { semelfactivo }\end{array}$ & $\begin{array}{l}\text { a. }[F I C A R+V 2 \text { NDO] } \\
\text { a gente chega } L A \bar{A} \text { a gente fica dançan::(d)o e ela some... (AC-010; NR:L. 96) } \\
\text { b. }\left[C O N T I N U A R+V 2 \_N D O\right] \\
\text { do dia que eu casei até hoje eu continuo na minha casa e cuidan(d)o do meus filhos (AC-110; NE: L. 81) } \\
\text { c. [ANDAR +V2_NDO] } \\
\text { tinha um que era mais bem de situação ia de cavalo aí:: (insultô(u)) lá né?... (vixe)... andô }(\mathbf{u}) \text { falan::(d)o } \\
\text { insultan(d)o né? essa coisa... (AC-063; NR:L.569) }\end{array}$ \\
\hline \begin{tabular}{|l|}
$(9)$ \\
Imperfect \\
cursivo \\
iterativo
\end{tabular} & $\begin{array}{l}\text { a. }\left[F I C A R+V 2 \_N D O\right] \\
\text { e eu fi/ e eu fico falan(d)o pra ela né?... que::... aquele carrinho::... éh:: sempre foi o que eu:: mais quis né? } \\
\text { no Natal }(\mathrm{AC}-011 ; \mathrm{NE}: \mathrm{L} .49) \\
\text { b. }\left[C O N T I N U A R+V 2 \_N D O\right] \\
\text { aí lá a gente assim continuố(u) mantendo contato a gente se falava todo dia... (AC-046; NE: L.74-75) } \\
\text { c. [ANDAR+V2_NDO] } \\
\text { já há alguns dias que ela anda me falan(d)o que ela/ que eles num tava legal:: tal (AC-022; NR: L.234) } \\
\text { d. }\left[V I V E R+V 2 \_N D O\right] \\
\quad \text { meu vizinho vive me chaman(d)o pra ajudá(r) ele (AC-010; RO: L. 339) }\end{array}$ \\
\hline $\begin{array}{l}(\mathbf{1 0}) \\
\text { Imperfectivo } \\
\text { cursivo } \\
\text { progressivo }\end{array}$ & $\begin{array}{l}\text { a. }\left[F I C A R+V \_N D O\right] \\
\text { nós tínhamos um painel que tinha uns quarenta plug... então simultaneamente fazia uns quarenta interur- } \\
\text { banos... só que tem cidade que tinha um aparelho... e uma linha... ((barulho de moto)) então um/ se tivesse } \\
\text { alguém falando... naquele cabo lá... ela ficava acumulando as pessoas... (AC-114; NE: L. 147) } \\
\text { b. [CONTINUAR + V2_NDO] } \\
\text { e vai continuá(r) aumentan(d)o as vagas... tá nítido isso... a universidade em si acabô(u) de acampá(r)... o } \\
\text { campus da FAMERP... (AC-080; RO: L.279) }\end{array}$ \\
\hline $\begin{array}{l}\text { (11) } \\
\text { Perfectivo } \\
\text { pontual }\end{array}$ & $\begin{array}{l}\text { a. }[F I C A R+V 2 N D O] \\
\text { eu fiquei saben }(\mathbf{d}) \text { o que ali no Vítor de manhã ali o ensino é::... é BOM ali né? (AC-015; RO: L. 931) }\end{array}$ \\
\hline
\end{tabular}

Fonte: Elaboração própria, com base em Fernandes (2010).

Dois pontos devem ainda ser destacados da observação das ocorrências prototípicas mostradas no quadro 2: (i) além da noção de aspecto, $V_{1}$ auxiliar comporta também noções de tempo e modo, formando a chamada cadeia verbo-para-TAM (HEINE, 1993), auxiliando $V_{2}$, na forma de gerúndio, a carregar tais informações; (ii) aspecto perfectivo pontual manifestado por $\left[V_{1-F I C A R}+V_{2}{ }_{2} N O\right]$ não compõe com os demais tipos aspectuais um mesmo subdomínio funcional de cursividade. 


\subsection{Aspectos metodológicos}

Sob o Princípio da estratificação defendemos, então, que as perífrases constituídas por [VI-ANDAR/CONTINUAR/FICAR/VIVER $\left.+V_{2} \_N D O\right]$ podem ser consideradas variantes de mesma variável dependente, à medida que, em sentido lato, se lida com construções diferentes para "mesmo" significado aspectual imperfectivo cursivo. Nuances aspectuais, como semelfactividade, iteratividade e progressividade, são captadas pelo controle variáveis semânticas independentes.

Os dados para esse estudo provêm da Amostra Censo do Banco de dados Iboruna (GONÇALVES, 2007), um banco de médio porte que registra a fala do interior paulista. Embora as 152 entrevistas sociolinguísticas que compõem o banco de dados sejam socialmente estratificadas (sexo, nível de escolaridade, faixa etária e nível socioeconômico), não apresentaremos resultados para variáveis sociais, na correlação com a variável dependente tipo de perífrase, dados os propósitos programáticos deste artigo.

Para testar o grau de gramaticalização das perífrases, adotamos dois critérios: (i) apuração de frequências token (ocorrência da perífrase independentemente de seu valor aspectual) e type (atualização em cada perífrase de nuanças aspectuais distintas); (ii) análise qualitativa de 10 critérios de auxiliaridade (cf. quadro 5), escolhidos dentre os mais recorrentes e menos controversos na literatura e aplicados a cada tipo de perífrase.

Quadro 5 - Critérios de auxiliaridade aplicados às perífrases

[VI-ANDAR/CONTINUAR/FICAR/VIVER + $\left.V_{2} \_N D O\right]$

\begin{tabular}{|l|l|}
\hline \multicolumn{1}{|c|}{ Critérios } & \multicolumn{1}{c|}{ Explicitação } \\
\hline 1. Inseparabilidade de $\mathrm{V}_{1} \mathrm{e} \mathrm{V}_{2}$ & $\mathrm{~V}_{1} \mathrm{e} \mathrm{V}_{2}$ não admitem material interveniente na perífrase. \\
\hline 2. Detematização de $\mathrm{V}_{1}$ & $\mathrm{~V}_{1}$ auxiliar não atribui papel temático a sujeitos e/ou complementos. \\
\hline 3. Escopo de negação & A negação incide sobre toda perífrase, e não sobre suas partes. \\
\hline 4. Sujeito único & $\begin{array}{l}\mathrm{V}_{1} \text { e } \mathrm{V}_{2} \text { têm sujeito único, com traços e papel temático determinados } \\
\text { por } \mathrm{V}_{2} .\end{array}$ \\
\hline 5. Irreversibilidade entre $\mathrm{V}_{1}$ e $\mathrm{V}_{2}$ & Ordem fixa $\left[V_{1}\right.$ auxiliar $+V_{2}$ auxiliado (em uma forma nominal)]. \\
\hline 6. Escopo de tempo & $\begin{array}{l}\text { Circunstante temporal incide sobre toda perífrase, e não sobre suas } \\
\text { partes. }\end{array}$ \\
\hline 7. V1 e $\mathrm{V}_{2}$ têm núcleo oracional único & $\mathrm{V}_{1}$ e $\mathrm{V}_{2}$ não podem ser desmembrados em núcleos oracionais distintos. \\
\hline 8. Apassivação & $\mathrm{V}_{1}$ é auxiliar se a equivalente passiva o inclui na mudança estrutural. \\
\hline 9. Recursividade & $\mathrm{V}_{1}$ e $\mathrm{V}_{2}$ admitem combinação de mesma raiz verbal. \\
\hline 10. Oposição a forma simples & Perífrases com auxiliares se opõem a forma verbal simples. \\
\hline
\end{tabular}

Fonte: elaboração própria, com base em Heine (1993) e Ilari e Basso (2008). 
Se um critério se atualiza em alguma ocorrência da perífrase analisada, consideramos então que ele se aplica àquele tipo de perífrase, independentemente da frequência com que se aplica. Quanto mais critérios atualizados para um dado tipo, maior seu grau de gramaticalização.

Para confirmar a hipótese de que as perífrases integram o mesmo domínio funcional e, portanto, mantêm significado equivalente, procedemos ao levantamento de todos os tipos de $V_{2}$ do córpus que ocorrem com os diferentes tipos de $V_{1}$ na formação de perífrases que concorrem na codificação de mesmo valor aspectual. Em outras palavras, se um mesmo tipo de $V_{2}$ ocorre com mais de um tipo de $V_{1}$ expressando mesma função aspectual, inequivocamente a escolha do falante poderia recair sobre qualquer tipo de $V_{1}$, configurando caso de variação.

\subsection{Resultados}

Partindo, agora, para os resultados, segue, na tabela 1, a apuração da frequência token/type, para os quatro tipos perifrásticos. ${ }^{6}$

Tabela 1 - Frequência de uso das perífrases aspectuais [ $\left.V_{\text {I-ANDAR/CONTINUAR/FICAR/VIVER }}\right]$

\begin{tabular}{|c|c|c|c|c|c|}
\hline Funções (types) & $\begin{array}{l}\text { ficar } \\
\text { (4) }\end{array}$ & $\begin{array}{l}\text { continuar } \\
\text { (3) }\end{array}$ & $\begin{array}{l}\text { andar } \\
(2)\end{array}$ & $\begin{array}{l}\text { viver } \\
(1)\end{array}$ & Total \\
\hline Imperfectivo cursivo semelfactivo & $\begin{array}{c}199 / 593= \\
33,4 \%\end{array}$ & $\begin{array}{c}47 / 74= \\
64,8 \%\end{array}$ & $\begin{array}{c}2 / 12= \\
16 \%\end{array}$ & - & $\begin{array}{c}249 / 691= \\
36 \%\end{array}$ \\
\hline Imperfectivo cursivo iterativo & $\begin{array}{c}289 / 593= \\
48,7 \%\end{array}$ & $\begin{array}{c}25 / 75= \\
33,7 \%\end{array}$ & $\begin{array}{c}10 / 12= \\
84 \%\end{array}$ & $\begin{array}{c}12 / 12= \\
100 \%\end{array}$ & $\begin{array}{c}335 / 691= \\
48,5 \%\end{array}$ \\
\hline Imperfectivo cursivo progressivo & $\begin{array}{c}2 / 593= \\
0,5 \%\end{array}$ & $\begin{array}{c}2 / 74= \\
1,5 \%\end{array}$ & - & - & $\begin{array}{c}4 / 691= \\
0,5 \% \\
\end{array}$ \\
\hline Perfectivo pontual & $\begin{array}{c}103 / 593= \\
17,4 \%\end{array}$ & - & - & - & $\begin{array}{c}103 / 691= \\
15 \%\end{array}$ \\
\hline TOTAL (tokens) & $\begin{array}{c}593 / 691= \\
86 \%\end{array}$ & $\begin{array}{c}74 / 691= \\
11 \%\end{array}$ & $\begin{array}{c}12 / 691= \\
1,5 \%\end{array}$ & $\begin{array}{c}12 / 691= \\
1,5 \%\end{array}$ & 691 \\
\hline
\end{tabular}

Fonte: Elaboração própria, a partir de Fernandes (2010).

Destacam-se da tabela 1 os seguintes resultados principais: (i) perífrase com $V_{1}$ FICAR é a mais frequente (86\%), com quatro types aspectuais distintos, e a única a codificar também aspecto perfectivo pontual; (ii) as demais perífrases manifestam apenas aspecto imperfectivo cursivo, com nuances aspectuais que as diferenciam, sendo a iteratividade o traço que une todas elas e o responsável por quase metade das ocorrências (48,5\%); (iii) 
a frequência token reflete diretamente o número de types atualizados por cada perífrase, o que é um indicativo de que quanto maior a frequência token maior o número de types.

Considerando agora os 10 parâmetros de auxiliaridade que, aplicados a casos prototípicos de cada tipo de perífrase, sancionam o estatuto mais ou menos gramaticalizado de cada uma delas, o resultado é o mostrado no quadro 6, aqui reinterpretado a partir do trabalho de Fernandes (2010).

Quadro 6 - Grau de auxiliaridade de perífrases [ $V_{\text {I-ANDAR/CONTINUAR/FICAR/VIVER }}$ ]

\begin{tabular}{|l|c|c|c|c|}
\hline Critérios $\quad[V 1+$ V2_NDO] & $\begin{array}{c}\text { V1- } \\
\text { ANDAR }\end{array}$ & $\begin{array}{c}\text { V1- } \\
\text { CONTINUAR }\end{array}$ & $\begin{array}{c}\text { V1- } \\
\text { FICAR }\end{array}$ & $\begin{array}{c}\text { V1- } \\
\text { VIVER }\end{array}$ \\
\hline 1. Inseparabilidade de $\mathrm{V}_{1} \mathrm{e} \mathrm{V}_{2}$ & 0 & 0 & 0 & 0 \\
\hline 2. Detematização de $\mathrm{V}_{1}$ & 0 & 0 & 0 & 1 \\
\hline 3. Escopo de negação & 0 & 0 & 0 & 1 \\
\hline 4. Sujeito único & 1 & 1 & 1 & 1 \\
\hline 5. Irreversibilidade entre $\mathrm{V}_{1} \mathrm{e} \mathrm{V}_{2}$ & 1 & 1 & 1 & 1 \\
\hline 6. Escopo de tempo & 0 & 0 & 0 & 1 \\
\hline 7. Vi e V2 têm núcleo oracional único & 0 & 0 & 0 & 1 \\
\hline 8. Apassivação & 1 & 1 & 1 & 1 \\
\hline 9. Recursividade & 0 & 0 & 0 & 0 \\
\hline 10. Opposição a forma simples & 1 & 1 & 1 & 1 \\
\hline Grau de gramaticalidade & $\mathbf{4}$ & $\mathbf{4}$ & $\mathbf{4}$ & $\mathbf{8}$ \\
\hline
\end{tabular}

N.B.: se um critério se aplica à perífrase atribui-se 1 ; se não se aplica, atribui-se 0 .

Fonte: Fernandes (2010; com adaptação).

O resultado do quadro 6 mostra que perífrase com $V_{1 \text {-VIVER }}$ seria a mais gramaticalizada, ao passo que os outros três tipos apresentam o mesmo grau de gramaticalização.

Confrontando os resultados de frequência, expostos na tabela 1, e os de grau de auxiliaridade, expostos do quadro 6, os clines de gramaticalidade resultantes seriam os dados no quadro 7 , a seguir. 
Quadro 7 - Clines de gramaticalidade [V $\left.\mathrm{V}_{\text {1-ANDAR/CONTINUAR/FICAR/VIVER }}+\mathrm{V}_{2 \_ \text {NDO }}\right]$

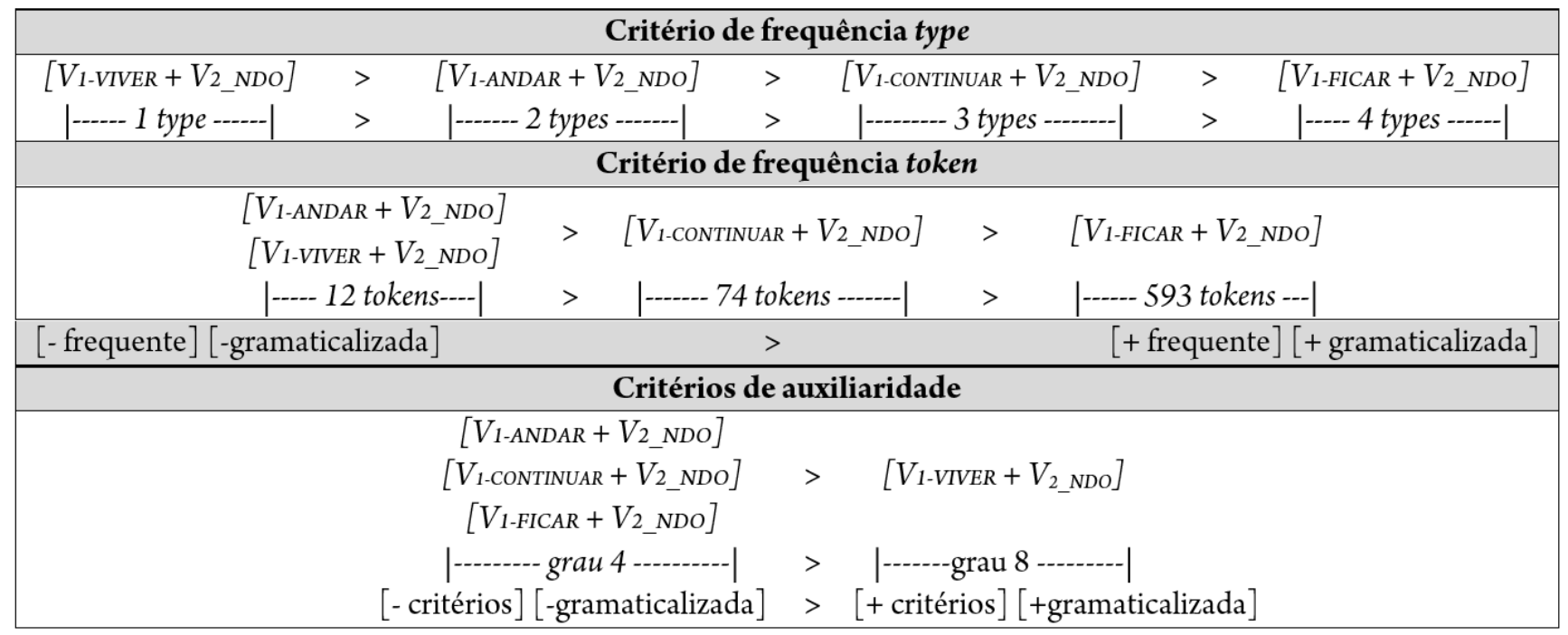

Fonte: Elaboração própria.

Em trabalho comparando perífrases de Aspecto, Tempo e Modalidade, formadas por $V 1_{\text {-IR }}+$ infinitivo e por $V_{\text {1-ANDAR/CONTINUAR/FICAR/VIVER }}+V_{\text {-NDO, Gonçalves e Freitag }}$ (2011) observam que a divergência entre os dois critérios (frequências token e type e auxiliaridade) se deve aos parâmetros de auxiliaridade adotados, uma vez que a baixa frequência token para $V_{\text {I-VIVER }}$ (apenas 12) restringe a verificação de sua multifuncionalidade (apenas o type iterativo) ao mesmo tempo em que reduz a possibilidade de atualização de um número maior de critérios de auxiliaridade. Situação contrária se verifica para os

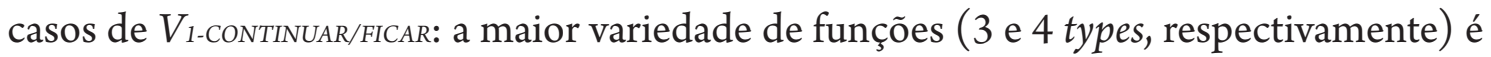
reflexo da alta frequência token (74 e 593, respectivamente). Ainda segundo os autores, corroborando a importância da frequência de uso como forte indício de gramaticalização (BYBEE, 2003), esse resultado permite a formulação mais geral de que o maior ou menor grau de gramaticalização de uma forma é sempre proporcional a sua maior ou menor frequência token/type. Assim, o cline mais seguro para afirmar a gramaticalização das perífrases aspectuais de imperfectivo é o baseado na apuração da frequência, o que colocaria,

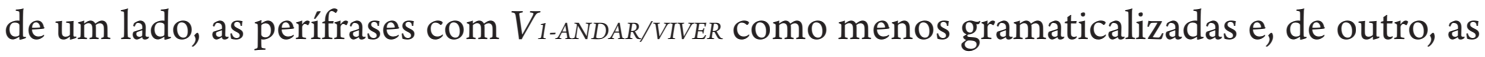

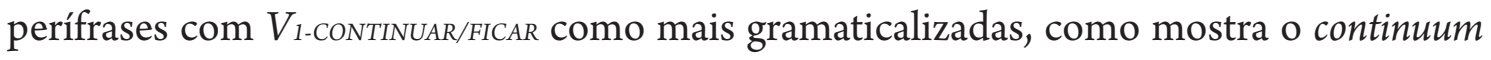
em (12), representativo de uma hipótese de mudança a ser diacronicamente atestada. 


\section{(12) Continuum de gramaticalização das perífrases aspectuais}

$\left.\left[V 1-V I V E R+V 2 \_N D O\right]>\left[V 1-A N D A R+V 2 \_N D O\right]>V 1-C O N T I N U A R+V 2 \_N D O\right]>\left[V 1-F I C A R+V 2 \_N D O\right]$

[- gramaticalizada]

[+ gramaticalizada $]$

\subsection{Identificando contextos de variação}

Para confirmar a viabilidade de um tratamento variável para os quatro tipos perifrásticos em exame, resta responder em que contextos eles podem ser considerados variantes de uma mesma variável ou camadas diferentes do mesmo domínio funcional. $\mathrm{O}$ resultado é o mostrado no quadro 8, dado a seguir, a partir do qual se observa que todas as perífrases constituem, de fato, casos de estratificação dentro do subdomínio aspectual de imperfectivo cursivo, não representando problema algum para um estudioso da variação e da gramaticalização considerá-las como formas variantes.

Quadro 8 - Perífrases alternantes em função de tipos de $V_{2 \_N D O}$.

\begin{tabular}{|c|c|c|c|c|c|}
\hline \multirow{2}{*}{$\begin{array}{c}\text { Codificação aspec- } \\
\text { tual }\end{array}$} & \multirow{2}{*}{$V_{2 \_N D O}$} & \multicolumn{4}{|c|}{ Formas Alternantes } \\
\hline & & V1-FICAR & V1-CONTINUAR & V1-ANDAR & V1-VIVER \\
\hline \multirow{19}{*}{$\begin{array}{c}\text { Imperfectivo cursivo } \\
\text { iterativo }\end{array}$} & Adquirir & $\sqrt{ }$ & & $\sqrt{ }$ & \\
\hline & Bater & $\sqrt{ }$ & $\sqrt{ }$ & & \\
\hline & Brigar & $\sqrt{ }$ & $\sqrt{ }$ & & $\sqrt{ }$ \\
\hline & Brincar & $\sqrt{ }$ & $\sqrt{ }$ & & $\sqrt{ }$ \\
\hline & Chamar & $\sqrt{ }$ & & & $\sqrt{ }$ \\
\hline & Colocar & $\sqrt{ }$ & $\sqrt{ }$ & & \\
\hline & Contar & $\sqrt{ }$ & & $\sqrt{ }$ & \\
\hline & Dar & $\sqrt{ }$ & $\sqrt{ }$ & & \\
\hline & Escrever & $\sqrt{ }$ & $\sqrt{ }$ & & \\
\hline & Falar & $\sqrt{ }$ & $\sqrt{ }$ & $\sqrt{ }$ & $\sqrt{ }$ \\
\hline & Fumar & $\sqrt{ }$ & $\sqrt{ }$ & & \\
\hline & Insistir & $\sqrt{ }$ & $\sqrt{ }$ & & \\
\hline & $I r$ & $\sqrt{ }$ & $\sqrt{ }$ & & \\
\hline & Mexer & $\sqrt{ }$ & $\sqrt{ }$ & $\sqrt{ }$ & \\
\hline & Passar & $\sqrt{ }$ & $\sqrt{ }$ & & \\
\hline & Preocupar & $\sqrt{ }$ & & & $\sqrt{ }$ \\
\hline & Procurar & $\sqrt{ }$ & & $\sqrt{ }$ & \\
\hline & Sair & $\sqrt{ }$ & & & $\sqrt{ }$ \\
\hline & Fazer & $\sqrt{ }$ & $\sqrt{ }$ & $\sqrt{ }$ & \\
\hline \multirow{4}{*}{$\begin{array}{l}\text { Imperfectivo cursivo } \\
\text { semelfactivo }\end{array}$} & Andar & $\sqrt{ }$ & $\sqrt{ }$ & & \\
\hline & Cuidar & $\sqrt{ }$ & $\sqrt{ }$ & & \\
\hline & Estudar & $\sqrt{ }$ & $\sqrt{ }$ & & \\
\hline & Jogar & $\sqrt{ }$ & $\sqrt{ }$ & & \\
\hline
\end{tabular}




\begin{tabular}{|c|c|c|c|c|c|}
\hline \multirow{7}{*}{} & Morar & $\sqrt{ }$ & $\sqrt{ }$ & & \\
\cline { 2 - 6 } & Namorar & $\sqrt{ }$ & $\sqrt{ }$ & & \\
\cline { 2 - 6 } & Pescar & $\sqrt{ }$ & $\sqrt{ }$ & & \\
\cline { 2 - 6 } & Trabalhar & $\sqrt{ }$ & $\sqrt{ }$ & & \\
\cline { 2 - 6 } & Valer & $\sqrt{ }$ & $\sqrt{ }$ & & \\
\cline { 2 - 6 } $\begin{array}{c}\text { Imperfectivo cursivo } \\
\text { progressivo }\end{array}$ & Aumentar & $\sqrt{ }$ & $\sqrt{ }$ & & \\
\hline
\end{tabular}

Fonte: Fernandes (2010, com adaptações).

Observamos ainda, no quadro 8, que a maior variabilidade de tipos de $V_{2 \_N D O}$ na

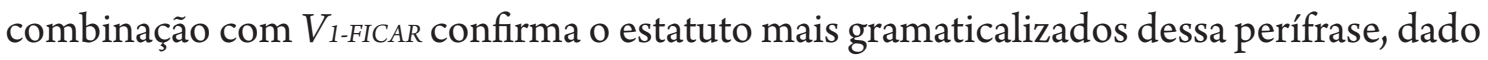
o maior número de contextos a que se aplica, por apresentar menor restrição semântica na combinação com $V_{2}$ NDO.

Para um estudo variacionista, se é o caso de o analista ter de estreitar o rigor de manutenção de mesmo significado referencial, as nuances de iteratividade, semelfactividade e progressividade podem requerer que se isolem contextos estritos de variação. Nesse caso, então, vários contextos variáveis se verificariam:

(i) todas as quatro perífrases variam na codificação de aspecto imperfectivo cursivo iterativo, como revela o caso de $V 2$-FALAR, que se combina com qualquer tipo de $V_{1}$ nessa acepção aspectual, como comprovam as ocorrências em (13).

(13) Contexto estrito de variação na codificação de aspecto imperfectivo cursivo iterativo a. eu ficava sempre falan(d)o - “um dia eu vô(u) passá(r) de lá vô(u) conhecê(r) ela”(AC-067; NE: L.8)

b. a gente continuô(u) se falan(d)o mas a gente num se via... (AC-021; NE: L.44)

c. já há alguns dias que ela anda me falan(d)o que ela/ que eles num tava legal:: tal (AC-022; NR: L.234)

d. minha mãe e meu pai... vivia falan(d)o pra mim estudá(r)... (AC-047; RO: L.300)

(ii) $V_{\text {l-ANDAR, }} V_{\text {l-CONTINUAR }} V_{\text {I-FICAR }}$ variam entre si na codificação de aspecto imperfectivo cursivo semelfactivo, como mostram as ocorrências em (14), com o mesmo tipo de

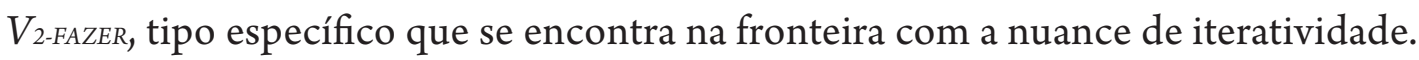


(14) Contexto estrito de variação na codificação de aspecto imperfectivo cursivo semelfactivo

a. ai eu acho uma coisa chata porque ela manda na tarefa e depois... eles fica fazen(d)o pergun::ta (AC-004; RO: L.266)

b. ao invés de eu faZê(r) a contabilidade pos meus clientes... eu fazia... continuei fazendo isso... [Doc.: hum] e comecei a implantá(r) esses sistemas (AC-099; NE: L.107)

c. e quando chegô (u) no ano de dois mil... ele andô(u) fazendo umas coisa muito errada (AC-132; NE: L.43)

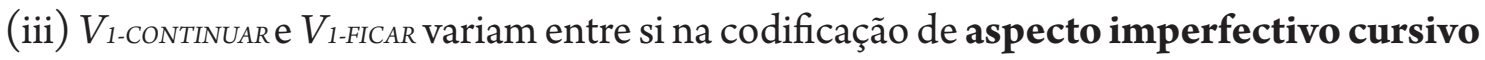

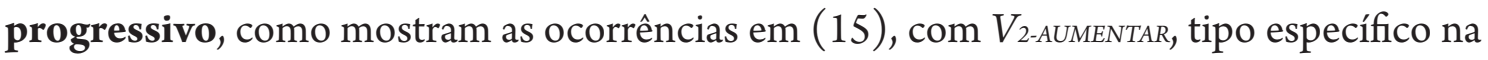
atualização da nuance progressiva.

(15) Contexto estrito de variação na codificação de aspecto imperfectivo cursivo progressivo

a. várias coisas éh o buraco na Camada de Ozônio tá se não me engano gele(i)ras no... pólo NORte e fica aumentando... a água no mar:: (AC-076; RP: L. 413)

b. vai continuá(r) aumentan(d)o as vagas... tá nítido isso... o governo já... além de tudo... o governo... acabô(u) de... a universidade em si acabô(u) de acampá(r)... o campus da FAMERP... (AC-080; RO: L. 279)

\section{Conclusão}

Neste trabalho, procuramos argumentar em favor da continuidade de trabalhos de interface entre TG e TVML, recorrendo a postulados teórico-metodológicos que as unem dentro de um quadro mais geral da pesquisa linguística voltado para o tratamento da mudança. Essa conciliação se revela eficaz na compatibilidade entre o conceito de regra variável e o Princípio da estratificação.

Atestamos empiricamente a adequação da proposta, investigando a gramaticalização de perífrases verbais de aspecto imperfectivo cursivo constituídas por diferentes tipos de $V_{1}$ auxiliar seguidos de forma nominal de gerúndio. Mostramos que, uma vez gramaticalizada, essas perífrases passam a integrar o mesmo subdomínio funcional de aspecto imperfectivo cursivo, ainda que tenhamos verificado que elas apresentam diferentes graus de gramaticalização, dada a natureza semântica dos tipos de $V_{1}$ que as constituem e a frequência de uso com que ocorrem no córpus.

Os resultados quantitativos permitiram demonstrar que as perífrases expressam em sua maioria aspecto imperfectivo cursivo (85\%), comprovando parcialmente a hipótese inicial, porque, além desse tipo aspectual, identificamos também o aspecto perfectivo 
pontual (15\%), que não participa do mesmo subdomínio funcional aspectual e, por isso, não pode ser incluído na implementação da regra variável. A análise da gramaticalização das perífrases levou em conta três aspectos: a frequência geral da perífrase (frequência token), sua multifuncionalidade (frequência type individual) e a atualização dos critérios de auxiliaridade para cada tipo. Na elaboração do cline de gramaticalização das formas perifrásticas, o critério de frequência token/type mostrou-se recurso metodológico mais eficaz do que o de aplicação dos parâmetros de auxiliaridade, o que, ao final, permitiu-nos chegar à formulação geral de que quanto maior a frequência de uma dada forma, maior a probabilidade de, numa escala de gramaticalização, ela representar a forma mais gramaticalizada, e quanto menor a frequência, maior a probabilidade de ela representar a forma menos gramaticalizada.

Com a investigação da alternância entre os diferentes tipos de perífrases, demonstramos que todas elas podem, indistintamente, ser consideradas como formas variantes, e a elas ser dispensado um tratamento quantitativo, num estudo de gramaticalização, aos moldes da TVML, se afrouxada a premissa de manutenção de mesmo significado referencial. Todavia, na exigência de manutenção de mesmo valor de verdade, para atender interesse de variacionistas, nuances aspectuais distintas (interatividade, semelfactividade e progressividade) passam a estreitar os contextos variáveis, selecionando apenas aquelas perífrases que cumprem exatamente a mesma função.

Mostrados os passos teórico-metodológicos que tornam compatíveis interesses de variacionistas e de estudiosos da gramaticalização dentro de um quadro sociofuncionalista, torna-se fácil compreender como o trabalho de investigação se implementaria daí em diante, na consideração de fatores/variáveis estruturais e/ou sociais que explicitem como a mudança se processa e como ela pode ser mais bem compreendida dentro de um ou de outro quadro teórico, seja em perspectiva sincrônica seja em perspectiva diacrônica.

Arrematando essa conclusão, reforçamos a orientação de Görski e Tavares (200-?) na empreitada de um estudo sociofuncionalista: cabe ao pesquisador adotar uma postura ou mais funcionalista, afrouxando o conceito de regra variável, na consideração de funções similares que diferentes formas cumprem num mesmo domínio funcional, ou mais variacionista, estreitando o foco de análise na consideração de formas divergentes que codificam um mesmo significado referencial. Assim, cada postura, ao evidenciar métodos e medidas distintos, porém compatíveis, mantém o compromisso com o modelo teórico que guia a investigação. 


\section{Referências}

BYBEE, Joan. Língua, uso e cognição. Tradução: Maria Angélica Furtado da Cunha; Sebastião Carlos Leite Gonçalves. São Paulo: Cortez, 2016. [Título original: Language, usage and cognition].

BYBEE, Joan. Mechanisms of change in grammaticalization: the role of frequency. In: JOSEPH, Brian; JANDA, Richard (Ed.). The handbook of historical linguistics. Oxford: Blackwell, 2003. p. 602-623.

BYBEE, Joan; HOPPER, Paul (Ed.). Frequency and the emergence of linguistic structure. Amsterdam: John Benjamins, 2001.

CASTILHO, Ataliba Teixeira de. Introdução ao estudo do aspecto verbal na língua portuguesa. Marília: Faculdade de Ciências e Letras, 1968.

CASTILHO, Ataliba Teixeira de. Aspecto verbal no português falado. In: ABAURRE, Maria Bernadete; RODRIGUES, Angela (Org.). Gramática do Português Falado: novos estudos descritivos. Campinas: Editora da Unicamp, 2002. v. VIII, p. 83-121.

COSTA, Sonia Barbosa. O aspecto em português. 3.Ed. São Paulo: Contexto, 2002.

ECKERT, Penelope. Three waves of variation study: the emergence of meaning in the study of variation. Annual Review of Anthropology, Palo Alto, v. 41, n.1, p. 87-100, 2012.

FERNANDES, Flávia Orci. Construções com os verbos andar, continuar, ficar e viver seguidos de gerúndio: um estudo na interface sociolinguística/gramaticalização. Orientador: Sebastião Carlos Leite Gonçalves. 2010. 91f. Iniciação Científica (Licenciatura em Letras) - Universidade Estadual Paulista/Fapesp, São José do Rio Preto, 2010.

GIVÓN, Talmy. From discourse to syntax: grammar as a processing strategy. In: GIVÓN, Talmy (Ed.). Syntax and semantics: discourse and syntax. New York: Academic Press, 1979.p. 81-112.

GONÇALVES, Sebastião Carlos Leite; FREITAG, Raquel Meister Ko. Da forma para função ou da função para forma? Guavira Letras, Três Lagoas, v. 13, n. 1., p. 89-107, 2011.

GONÇALVES, Sebastião Carlos Leite. Banco de dados Iboruna: amostras eletrônicas do português falado no interior paulista, 2007. Disponível em: http:://www.iboruna.ibilce. unesp.br. Acesso em: 15 jul. 2007.

GONÇALVES, Sebastião Carlos Leite. Gramaticalização, modalidade e evidencialidade: um estudo de caso no português do Brasil. Orientador: Maria Luiza Braga. 2003. 250f. Tese (Doutorado em Linguística) - Universidade Estadual de Campinas, Campinas, 2003.

GÖRSKI, Edair Maria. A questão do continuum na interface variação/gramaticalização. In: MATZENAUER, Carmen Lúcia Barreto et al. (Org.). Estudos da linguagem. Círculo de Estudos Linguísticos do Sul. Pelotas: EDUCAT, 2008. v. VIII, p. 145-172.

GÖRSKI, Edair Maria; GONÇALVES, Sebastião Carlos Leite; LUCHESI, Dante. Os estudos de variação: balanço crítico e panorama atual. 2015. Mesa-redonda apresentada no 59. Seminário do GEL, Bauru, 2011. 
GÖRSKI, Edair Maria e al. Mudança em fenômenos discursivos via variação e gramaticalização: o papel dos fatores sociais. Estudos Linguísticos, São Paulo, v. 32, n.1, [s.p.], 2003a. Disponível em: http://www.gel.hospedagemdesites.ws/estudoslinguisticos/ volumes/32. Acesso em: 1 jul. 2020.

GÖRSKI, Edair Maria et al. Fenômenos discursivos: resultados de análises variacionistas como indícios de gramaticalização. In: RONCARATI, Cláudia; ABRAÇADO, Jussara (Org.). Português brasileiro: contato linguístico, heterogeneidade e história. Rio de Janeiro: 7 Letras, 2003b. p. 106-122.

GÖRSKI, Edair Maria et. al. Gramaticalização/discursivização de itens de base verbal: funções e formas concorrentes. Estudos Linguísticos, São Paulo, v. 31, n. 1., [s.p.], 2002. Disponível em: http://www.gel.hospedagemdesites.ws/estudoslinguisticos/ volumes/31. Acesso em 1 jul. 2020.

GÖRSKI,EdairMaria;TAVARES, MariaAlice. Teoria da variação/mudança efuncionalismo linguístico: (in)compatibilidades? [200-?]. 30 p. Trabalho não publicado.

GÖRSKI, Edair Maria; TAVARES, Maria Alice. Reflexões teórico-metodológicas a respeito de uma interface sociofuncionalista. Revista do GELNE, Natal, v. 15, n.1/2, p. 75101, 2013. Disponível em https://periodicos.ufrn.br/gelne/article/view/9411. Acesso em 1 jul. 2020.

HEINE, Bernd. Auxiliaries: cognitive forces and grammaticalization. New York/Oxford: Oxford University Press, 1993.

HEINE, Bernd; NARROG, Heiko; LONG, Haiping. Constructional change vs. Grammaticalization. Studies in Language, Amsterdam, v. 40, n. 1, p. 137-175, 2016.

HOPPER, Paul. Emergent grammar. Berkeley Linguistic Society, Berkeley, v. 13, p. 139-57, 1987.

HOPPER, Paul. On some principles of grammaticization. In: TRAUGOTT, Elizabeth; HEINE, Bernd (Ed.). Approaches to grammaticalization. Philadelphia: John Benjamins Publishing Company, 1991.p. 17-35.

HOPPER, Paul; TRAUGOT, Elizabeth. Grammaticalization. Cambridge: Cambridge University Press, 1993.

ILARI, Rodolfo; BASSO, Renato Miguel. O verbo. In: ILARI, Rodolfo et al. (Org.). Gramática do Português Culto Falado no Brasil. Campinas: Editora da Unicamp, 2008. v. II, p. 163-365.

LABOV, William. Sociolinguistics patterns. Philadelphia: Philadelphia University Press, 1972.

LABOV, William. Principles of Linguistic Change: internal factors. Oxford: Blackwell, 1994.

LAVANDERA, B. Where does the sociolinguistic variable stop? Language in society, Cambridge, v. 7, n.2, p. 171-182, 1978. 
LOBATO, Lúcia Maria Pinheiro. Os verbos auxiliares em português contemporâneo. Critérios de Auxiliaridade. In: LOBATO, L. et al. Análises Linguísticas. Petrópolis: Vozes, 1975. p. 27-91.

LONGO, Beatriz N. de Oliveira; CAMPOS, Odette Gertrudes L. A de Souza. A auxiliaridade: perífrases de tempo e de aspecto no português falado. In: ABAURRE, Maria Bernadete; RODRIGUES, Angela (Org.). Gramática do Português Falado: novos estudos descritivos. Campinas: Editora da Unicamp, 2002. v. VIII, p. 445-497.

NARO, Anthony Julius; BRAGA, Maria Luiza A interface sociolinguística/ gramaticalização. Niterói, Gragoatá, v.9, n. 1, p. 125-134, 2000.

NARROG, Heiko; HEINE, Bernd (Ed.). The Oxford Handbook of grammaticalization. Oxford: Oxford University Press, 2011.

NEVALAINEN, Tertu; PALANDER-COLLIN, Minna. Grammaticalization and Sociolinguistics. In: NARROG, Heiko; HEINE, Bernd (Ed.). The Oxford Handbook of grammaticalization. Oxford: Oxford University Press, 2011. p. 118-129.

NEVES, Maria Helena de Moura. Estudos funcionalistas no Brasil. DELTA, São Paulo, v. 15, n. esp., p. 70-104, 1999.

NEWMEYER, Frederick. Deconstructing grammaticalization. Language Science, Amsterdam, v. 23, n. 2-3, p. 187-229, 2001.

PAIVA, Maria Conceição; GÖRSKI, Edair Maria; GONÇALVES, Sebastião Carlos Leite. Variação e mudança sob perspectiva do Sociofuncionalismo Linguístico. 2015. Mesa-redonda apresentada no VI Seminário de Sociolinguística, Vitória, ES, 2015.

POPLACK, Shana. Grammaticalization and linguistic variation. In: NARROG, Heiko; HEINE, Bernd (Ed.). The Oxford Handbook of grammaticalization. Oxford: Oxford University Press, 2011.p. 209-224.

POPLACK, Shana; TAGLIAMONTE, Sali. Nothing in context: variation, grammaticization and past time marking in Nigerian Pidgin English. In: BAKER, Philip; SYEA, Anand (Ed.). Changing meanings, changing functions. Papers relating to grammaticalization in contact languages, v.2. London: University of Westminster Press, 1996. p. 71-94.

SCRIPTA. Belo Horizonte: PUC Minas, 1997-. ISSN 1516-4039. 2001.

SOARES DA SILVA, Augusto. A Sociolinguística Cognitiva: razões e objecto de uma nova área de investigação linguística. Revista Portuguesa de Humanidades - Estudos Linguísticos, Braga, PT, v. 13, fasc. 1, p. 191-212, 2009.

TAVARES, Maria Alice. A gramaticalização de E, AÍ, DAÍ e ENTÃO: estratificação/ variação e mudança no domínio funcional da sequenciação retroativo-propulsora de informações - um estudo sociofuncionalista. Orientador: Edair Maria Görski, 2003. 302f. Tese (Doutorado em Linguística) - Universidade Federal de Santa Catarina, Florianópolis, 2003. 
TAVARES, Maria Alice; GÖRSKI, Edair Maria. Sociofuncionalismo: da teoria à prática pedagógica. In: SILVA, Camilo Rosa; HORA, Dermeval da; CHRISTIANO, Maria Elizabeth (Org.). Linguística e práticas pedagógicas. Santa Maria: Palloti, 2006. p. 127148.

TAVARES, Maria Alice; GÖRSKI, Edair Maria. Variação e Sociofuncionalismo. In: MARTINS, Marco Antonio; ABRAÇADO, Jussara (Org.). Mapeamento sociolinguístico do português brasileiro. São Paulo: Contexto, 2015. p. 249-270.

TRAVAGLIA, Luiz Carlos $O$ aspecto verbal no português: a categoria e sua expressão. Uberlândia: Gráfica da UFU, 1981.

TRAUGOTT, Elizabeth; TROUSDALE, Graeme. Constructionalization and constructional change. Oxford: Oxford University Press, 2013.

TROUSDALE, Graeme. On the relationship between grammaticalization and constructionalization. Folia Linguistica, Berlim, v. 48, n.2, p. 557-578, 2014.

WEINREICH, Uriel; LABOV, William; HERZOG, Marvin. Empirical foundations for a theory of language change. In: LEHMAN, Winfred; MALKIEL, Yakov (Ed.). Directions for historical linguistics. Austin: University of Texas Press, 1968. p. 97-195.

Data de submissão: 06/08/2020

Data de aceite: 02/10/2020 